\title{
Visual Autofiction: A Strategy for Cultural Inclusion
}

Karen Ferreira-Meyers and Bontle Tau

This chapter considers the use of autofiction as a visual storytelling method by contemporary artists, a practice designed to initiate cultural inclusion within a field that has historically favored European visual narratives and excluded many others. Here we consider the autofictional as a literary form that rests in between autobiography and fiction, creating a space in which fact and fiction can coexist within a single testimonial. While it originated as a literary term, autofiction has since been interpreted and integrated, as a concept, into various other creative forms, including the visual arts (de Bloois 2007; Ahmed 2014). One of the dominant issues currently being addressed within the visual arts, a traditionally Western European field of practice, is that of cultural inclusion and decolonization within broader visual narratives. This chapter contends that contemporary artists are tackling this issue through the innovative methods of visual autofiction they employ to represent their experiences through their

\footnotetext{
K. Ferreira-Meyers $(\bowtie)$

Institute of Distance Education, University of Eswatini, Kwaluseni, Eswatini

B. Tau

Bloemfontein, South Africa

(C) The Author(s) 2022

A. Effe, H. Lawlor (eds.), The Autofictional, Palgrave Studies in

Life Writing, https://doi.org/10.1007/978-3-030-78440-9_9
}

161 
creative practice. These artists use autofiction as a storytelling strategy in order to construct a multiform and multifaceted narrative that foregrounds the diversity of selves and stories in the visual arts, further supporting the overall aim of cultural inclusion within representations in the field.

One of the key freedoms afforded by autofiction is that of self-narration undertaken from a variety of perspectives. Autofiction challenges the factuality of autobiography, in terms of its concrete and verifiable truth, in combining any such truth with aspects of fiction and fictionalization (Ferreira-Meyers 2012, 2015, 2018). In so doing, it opens up the possibility of a practice of self-narration which can be ever-changing in terms of viewpoint, mode, and its potential reception by an audience. While the fictional maintains its creative freedom, its placement in such close proximity to the perceived factual elements of autobiography persistently critiques the authenticity and stability of the autobiographical. The act of "narrating the self" is revealed instead as taking place in a reality that is created by and particular to the author. As autofictional practice draws attention to the "trickery" behind this narration, it reveals a different kind of truth behind the autobiographical account: the author or artist's subjective desire to present themselves in a certain manner. The foregrounding of the subjective angles from which the self can be viewed and represented is a key focus in visual art, and nowhere more so than in the domain of self-portraiture.

In its most basic definition, a self-portrait is "a representation of oneself made by oneself" (MoMA 2021). Ben Grant mentions, in his chapter in this volume, the importance of recognizing self-portraiture as synonymous in visual and literary practice. He argues that the prerequisite for a self-portrait across mediums is the absence of a continuous narrative, giving the creators of these self-portraits the liberty to present themselves without the usual (autobiographical) constraints such as chronology or logical order (this volume, 288). It is important to recognize, however, that more than a creative practice, the self-portrait posits a metaphysical awareness of what constitutes the "self." The artist is first required to recognize the "self," that is, before attempting to represent the "self" (Crozier and Greenhalgh 1988). As the MoMA glossary definition implies, artists are given the opportunity to "re-present" themselves in various modes, each time presenting the audience with a new self-narrative. "Truthfulness" in the self-portrait becomes negotiable due to the multiple, differing, and at times contradictory portrayals of the self. As in autofiction, these multiple versions offer a kind of fictionalized account of the "self." Dating 
back to the early Renaissance, the self-portrait has been a critical component of the formal training and identity of a visual artist (Smith 2001). It is regarded as an essential tool in their arsenal, and, for this reason, the majority of practicing artists will have made a self-portrait in the course of their career.

A long-standing dilemma in the institution of the visual arts has been the need for more inclusive representation of subjects from various cultural backgrounds, as in the "canon" of the Fine Arts, only one cultural group has been broadly and accurately represented. The initial parameters of the Fine Arts or "Beaux Arts," as an institution for recognition, training, and cultural appreciation for the arts, were set in a European context. While prehistoric art originates primarily in the African continent, the formalization of creative visual practice- that is, where art was recognized as a profession-takes place in Europe. As a result, the most influential art institutions are informed by European visual representations. In a twentyfirst-century context, while many racial and cultural groups form part of the framework of practicing visual artists, the parameters of cultural representation within the field are too narrow to accommodate the variety of practitioners, and indeed the variety of their works. The multicultural contemporary artist is thus left to subscribe to a predetermined Western narrative and to contend with the notion of the "Old Masters" of the Fine Arts, as well as the visual narratives chosen by them. As recognized "Old Masters" were predominantly European males, their methods of representation operated from a single cultural and gendered perspective, bringing that particular visual perspective to the fore. Contemporary artists who are not part of this former cultural narrative thus face the task of finding innovative methods to include themselves, or individuals of a similar background, within a visual narrative that did not accommodate them previously. In order to figuratively insert themselves into the visual canon, some artists adopt what we refer to as an "autofictional approach" through their various interpretations of what constitutes a self-portrait. The freedom to "fictionalize truths" provides these artists, or "visual storytellers," with the means to highlight social issues and unjust realities, using strategies that are playful, subtle, and layered. It affords non-European artists in particular a space in which to imagine themselves into the "canon" of self-portraiture.

Bontle Tau, a visual artist from South Africa, uses what she refers to as "autofictional practice in self-portraiture" to create a multicultural representational platform, in an effort to encourage the decolonization of the visual art canon, through inserting herself as a representative of an 
often-excluded subject in the historically recognized Fine Art narrative, the black female. Tau forms part of a large collective of contemporary African artists who address their desire to be represented within this narrative through imaginative visual storytelling strategies. Her primary medium of choice is self-portrait photography, which she perceives to be a deceptive medium. As a photographer, Tau pays mind to the popularized quotation from Richard Avedon, which states: "All photographs are accurate, but none of them tell the truth" (Avedon 1993). In acknowledging the role of the photographer as one who manipulates the content of the image through framing, composition, light, and perspective, Tau is able to operate within an imaginative and fluctuating mode of self-expression.

\section{The Role of Cultural Mimicry in Autofictional Practice}

As a polyglot who speaks seven languages, Tau's work focuses on the navigation of a multilingual cultural identity. In her artistic practice, she constantly questions the authenticity of the self as she witnesses the change in her self-expression when moving between languages. French is one of the more recent languages she has acquired and also one of the languages that she has explored most extensively. Her interest in the language lies in its "inaccessibility," as she lives in a non-Francophone nation, as well as in the historical-colonial ties between France and Africa, which still have an important impact on African societies today. As a visual artist and researcher in Fine Arts, Tau recognizes the traceable influence of the French École des Beaux Arts, which has shaped the structure and training methods of many contemporary art schools, even in South Africa. Conscious of the former colonial relationships between Africa and France, Tau sees her identity as that of an African artist and the encounter with the French language and culture as an inevitable conversation of cultural exchange.

Tau employs various visual storytelling techniques to project herself, or representations of people like her, into canonical and influential visual narratives. As a point of departure in her oeuvre, Tau considers the work of social linguist M.A.K. Halliday who states that language is something which can be performed and, more specifically, can serve as a medium for social performance in a given social (or cultural) setting. In his book Language as Social Semiotic: The Social Interpretation of Language and Meaning (1978), Halliday portrays language as something which exists on 
a social field. By "social field," he refers to any cultural setting such as a classroom, a boardroom, or even a casual social setting such as a restaurant or coffee house. Within this particular social field, Halliday identifies a "role-play" which takes place between those present. This refers to the position each individual takes in a given social field or the "role" that is played in each cultural setting. Halliday further identifies a "mode": the medium through which the language is performed and received, be it speaking, listening, reading, or writing (Halliday 1978, 53). In Tau's Mirror Series (2018) of self-portraits, she allows herself the freedom to play a range of linguistic and cultural roles by photographing herself in a mirror with asemic writing (illegible writing or marks that resemble writing but do not have any meaning), a visual symbol of a universal language smokescreen through which she moves in and out of these different roles. The "smokescreen" depicted in Tau's images enables her to adopt different poses, thus representing different cultural gestures.

"The Look of Reading (After Garrett Stewart)" (Fig. 9.1) was created in response to the work of the same name by literary theorist Garrett Stewart which explores the visual representation of the act of reading. In this work, Stewart analyzes the visualization of "thinking" that takes place through reading, paying tribute to the use of the book as a prop in classic or traditional painted portraits in order to portray an enlightened individual. Notably, the subjects who were placed in the role of "reader" and/ or that of an enlightened individual were commonly women in a seated posture (Stewart 2009). Tau's response to Stewart's work was to adopt this very position of the "enlightened" woman. In this image, Tau interacts with a series of Larousse books, one of the most widely recognized publishing houses of classic French literature, casting herself in the role of the seated woman who reads to enrich her mind and to pass the time. Second only to nobility, the subject in question-a woman taking on the role of the reading scholar-is one of the most highly esteemed subjects portrayed in portraiture. In imagining herself into the Western tradition of women in portraiture, Tau highlights the absence of representations of black women in the classical canon. Her imaginative autofictional representation inscribes the black female into this esteemed artistic tradition.

In Fig. 9.2, "L'Inscription" (The Inscription) (2018), Tau positions herself behind the smokescreen in order to subscribe to a specific lingual identity, in this case, Francophone, in keeping with the French title of the work. Her gesture of leaning forward and her imitation of the act of writing, together signify the act of "signing up" for this identity. Taken 


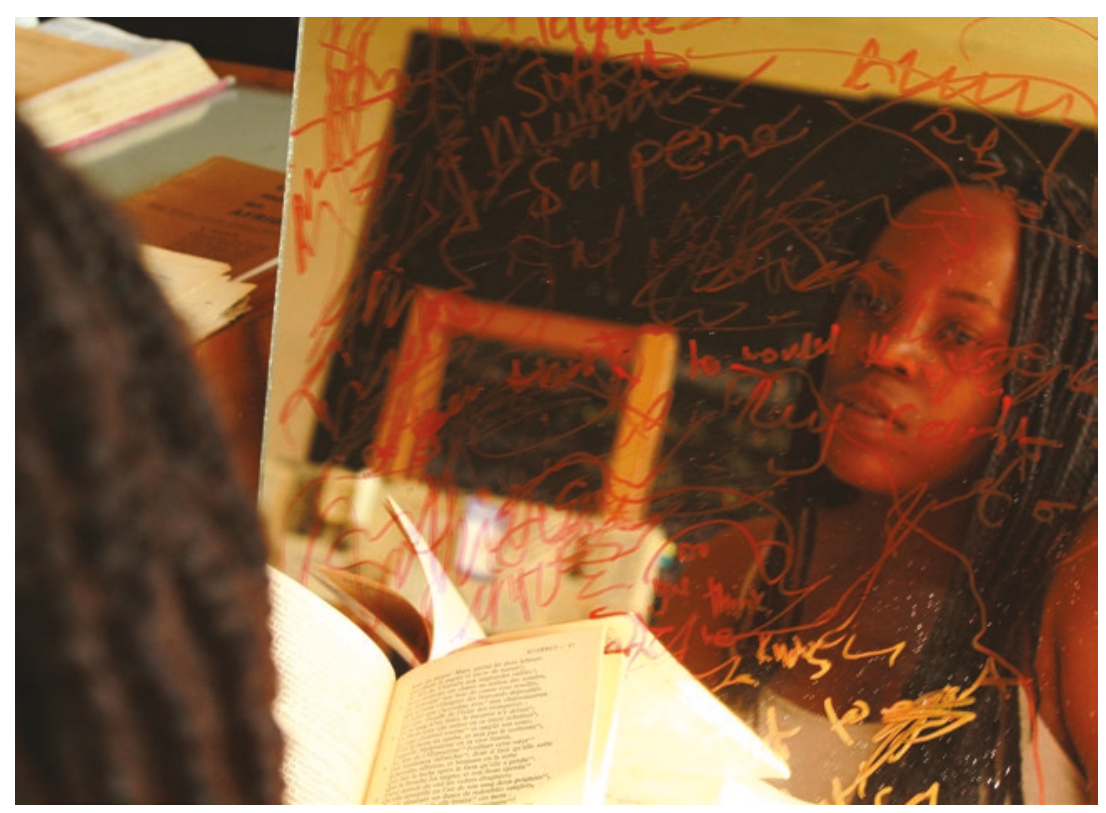

Fig. 9.1 "The Look of Reading (After Garret Stewart)," 2018. Digital SelfPortrait Photograph

through a mirror, a surface that distorts the presentation as well as the perception of the self, both these images speak to the autofictional representation and reception of the self. The distortion of reality symbolized by the mirror is discussed by Stephen Paul Miller (1993) with reference to the sixteenth-century painter Francesco Parmigianino who, through a convex mirror, attempted to capture everything in his studio in one single view. His objective was to represent everything that appeared on his threedimensional mirror as truthfully as possible onto a two-dimensional circular canvas. Parmigianino called this his "Self-Portrait in a Convex Mirror" (1524). A flat, conventional mirror, according to Miller, cannot achieve this all-encompassing effect, which is where the affordance of autofiction comes in. While a convex mirror creates images that are obviously distorted, it can capture everything. A flat mirror, on the other hand, does not capture everything before it, but presents a more mimetically "correct" image than the convex one. Tau's use of a flat mirror indicates her wish to be truthful to reality while also recognizing the fact that not "all" 


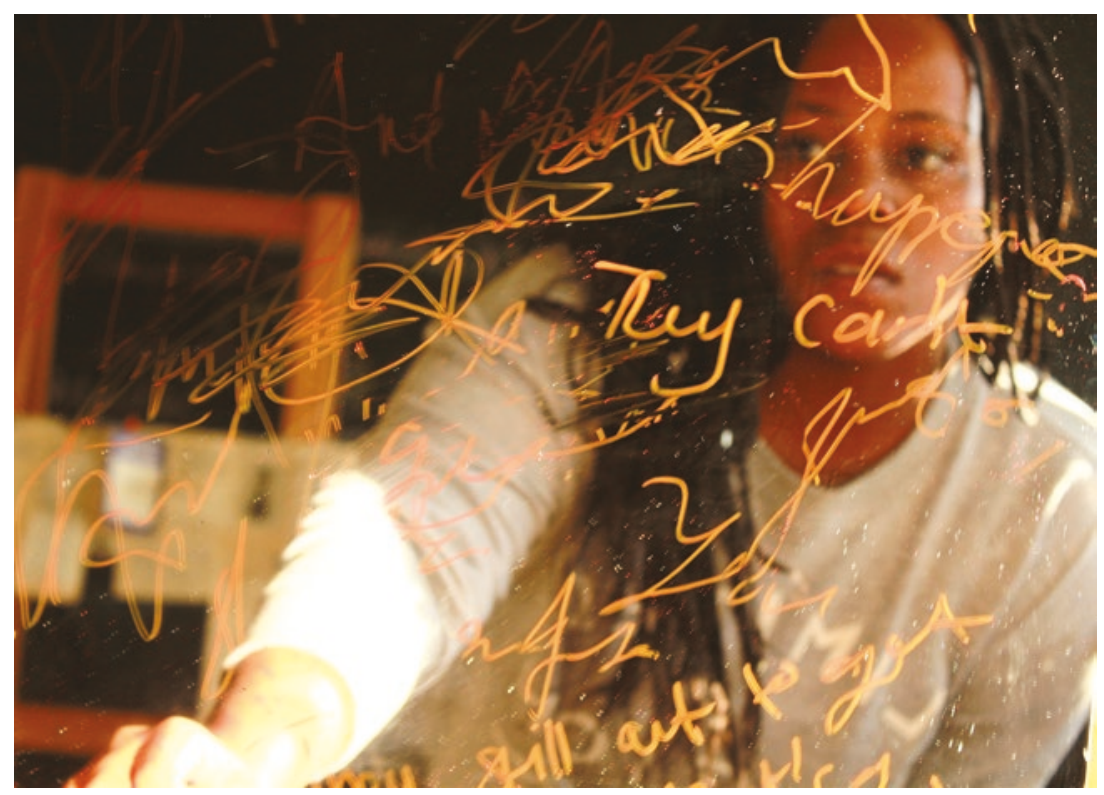

Fig. 9.2 “L'Inscription,” 2018. Digital Self-Portrait Photograph

reality can be captured. As autofictional practice grapples with the concepts of truth and factuality or "reality," in this case, in the process of selfnarration, Tau's use of the mirror as a vessel to present the "self" constitutes a visual autofictional tool in her own practice of self-narration.

Tau's multiple lingual identities fuse together her self-representation in autofictional practice-which in art necessitates a recognizable reproduction of the self-with an individual who operates or speaks toward a colonial expression through imitation and mimicry. The mirror in this work plays a significant role in this regard, insofar as it also symbolizes a distortion of the self. As mentioned in the case of Miller, we see an incomplete representation of the self and its immediate environment through the flat mirror; simultaneously, the notion of "doubling" is brought to mind, as one is inherently aware of the "original" self that the mirror reflects. The question of authenticity when expressing oneself through different cultural identities comes to the fore as Tau investigates whether or not she will maintain (aspects of) her former cultural identities, after she has acquired new ones. In The Location of Culture (1994), Homi Bhabha 
describes "mimicry" as a response to the African postcolonial movement, a term which he coined to describe the previously colonialized society's adoption of new languages and assimilation of a new cultural identity. Mimicry, according to Bhabha, is "a form of double articulation [which] appropriates the other as it visualizes power" (Bhabha 1994, 86). It allows one to adopt the cultural and lingual tendencies of another ethnic group (which in Bhabha's understanding is a dominant, colonial group) while maintaining and continuing to express the lingual and cultural tendencies they possessed before encountering this foreign culture. Mimicry is the resultant simultaneous expression of two or more cultures that have interacted within an individual. In the act of mimicking colonial discourse, the individual thus becomes layered, and indeed enhanced, in the domain of (visual) language and culture (Bhabha 1994). Far from being left powerless and non-identifiable, the individual has mastered what was previously considered to be the "master's" tongue. The subversive and playful approach to "mimicking" another cultural identity as well as distorting the self or the environment in which one finds oneself, finds an ideal vehicle in autofictional portraiture, in which the artist visualizes a desired alternate self, using a real-life environment or version of the self to do so. It also assists the artist in creatively projecting themselves into a cultural visual narrative that is not their own.

\section{Cultural Assimilation and Language Loss}

In her personal quest to authenticate her identity, an identity that is now informed by multiple lingual and cultural perspectives, autobiographical elements become important for Tau's oeuvre as she looks to her heritage for answers in relation to her cultural choices and pursuits in the present. Tau describes herself as having been an "inside child" during her childhood: her family sought to keep her away from the township (in South Africa, a "township" refers to a suburb or city of predominantly blackand often poor or working class-occupation, formerly designated for black occupation by apartheid legislation). They feared that she would be "contaminated" by the culture of these streets, a contamination that would be frowned upon in her future personal and professional pursuits. The "inside" in Tau's case pertains to her grandmother's home in Bochabela, in the Free State, where she was prohibited from participating in township cultural customs and behavior, which included speaking creolized versions of her home language, Sesotho. Instead, Tau explains that 
she was encouraged to practice Western spoken languages such as English in the home, cut off from the very different cultural and lingual environment that was mere meters away. For many African families like Tau's, access to Western culture and language equates to access to the kind of spaces which will offer success and opportunity. This preoccupation with access, according to Tau, is a prevailing social issue in African households, where assimilation is held in high esteem owing to the cultural domination exercised by a single group in their colonial cultural history.

French postcolonial writers form the framework of Tau's research portfolio, including the acclaimed French Caribbean writer Maryse Condé, who was awarded the Nobel Prize in Literature in 2018 following the publication of her autobiography entitled La Vie sans fards (What Is Africa to $M e$ ?) (2014). In response to Condé's text, Tau created a series of photographic portraits, including two self-portraits which evoke the ways in which her childhood was shaped by the pursuit of cultural assimilation.

The two portraits, "Je t'attends, je t'attends là pendant toute ma vie" (I'll wait for you, I'll wait here for you all my life) (Fig. 9.3) and "En
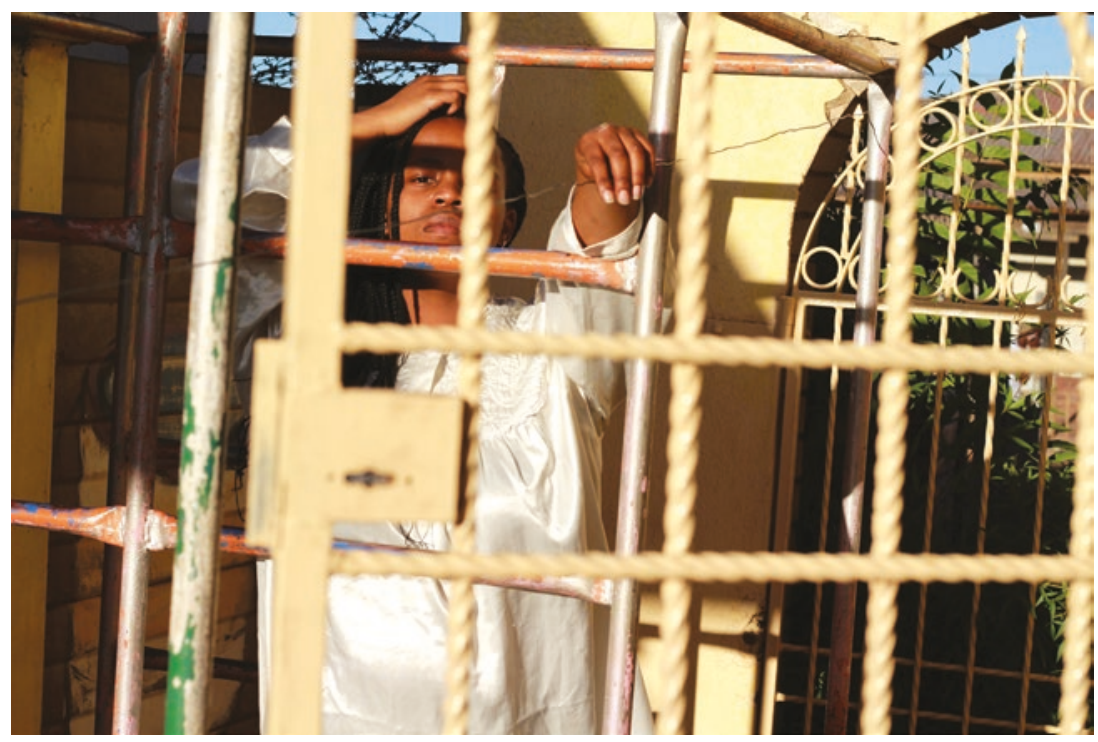

Fig. 9.3 "Je t'attends là, je t'attends là pendant toute ma vie," 2020. Digital Self-Portrait 
regardant mes peuples" (Looking at my peoples) (Fig. 9.4) depict Tau in the backyard of her late grandmother's home in Bochabela. Tau wears her grandmother's nightgown, which was fashioned to emulate a European design, and stands passively in a jungle gym that was placed inside the yard for her to play on during her childhood. In "Je t'attends, je t'attends là pendant toute ma vie," Tau assumes the role of acquiescent prisoner. She describes herself as emulating in this image the ghost of her grandmother in the hope of her return, a figure whom she believes to have been the only authentic reminder of her own Sesotho heritage. In "En regardant mes peuples," by contrast, Tau's position transforms the setting, formerly portrayed as a prison, into a stronghold. Here, Tau takes refuge in the confines of her inside position, adopting a stance in which she looks downward onto any outsider from her confines of assimilation. In this image, perception and point of view become critical, as the shadow of a bar from Tau's confining jungle gym is cast over her eyes, making subject and viewer alike physically and metaphorically "blind" to one another through this particular portrayal of self.

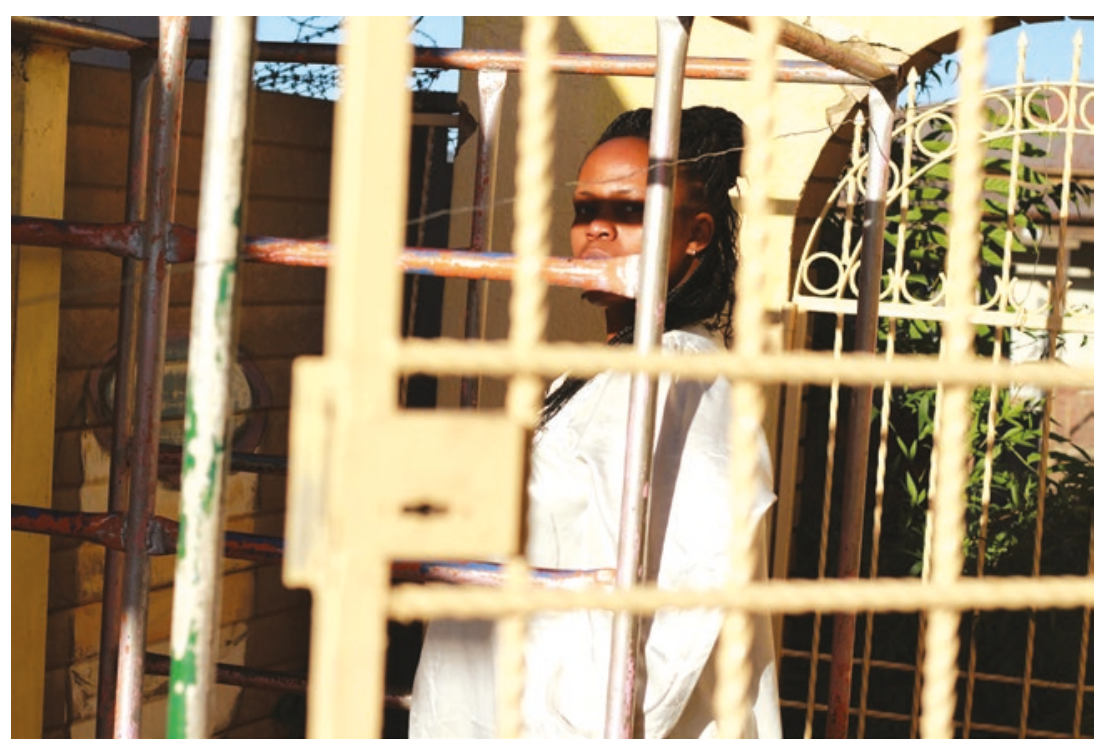

Fig. 9.4 "En regardant mes peuples,” 2020. Digital Self-Portrait 
Through these images, Tau puts into dialogue the two very different positions that she adopts in the same setting as a comment on assimilation and self-expression within a cultural narrative. Together, the images remind us of the impact of assimilation on identity, in which ties to former cultural "selves" must be relinquished in the adoption of a dominant cultural identity. Tau considers the loss of her Sesotho cultural identity as a prerequisite for mastering English and French. In her endeavor to immerse herself more fully in the cultures that these dominant languages represent, neglecting (parts of) her mother tongue becomes a necessary part of the process. The consequential loss of language is addressed by Joshua A. Fishman in What Do You Lose When You Lose Your Language? (1996), where he discusses the intergenerational loss of ethnic languages in favor of a dominant language. Fishman describes a first-generation immigrant who is bilingual, but who sacrifices their ethnic mother tongue for a dominant language. Imparted less and less to each new generation, the mother tongue is eventually lost (80-91). Tau addresses the issue of language loss through this pair of images, which represent the paradoxical nature of language acquisition: the gain of one lingual identity, for the loss of another. Tau grapples with the nostalgia for her Sesotho heritage in these two images by projecting elements of her memory and her imagination onto the artworks. While she visualizes herself in a position of "power" within the stronghold of a European cultural identity, by autofictionally evoking the Eurocentric aspects of her childhood, the images subtly remind us of her longing for the African self that she leaves behind, as she returns to the last memorable location which possessed remnants of her culture.

\section{Imagining the "Self" Through Time and Memory}

A common practice in traditional self-portraiture is the depiction of the artist over time. This practice is visible in the canonical work of many of the "Old Masters" such as Caravaggio, Monet, Rembrandt, Da Vinci, and even Van Gogh in their self-portraits at different life stages, portraits which have been permanently etched in the visual narrative of self-portraiture, to be studied and valued for centuries after their creation (Woods-Marsden 1998, 295). In Tau's attempt to expand the parameters of this institutionalized practice, she projects the same narrative onto her self-portraiture as she copies a portrait of herself as a child in "Of Another Time When I Existed" (Fig. 9.5). It is important to note that, while examples of the 


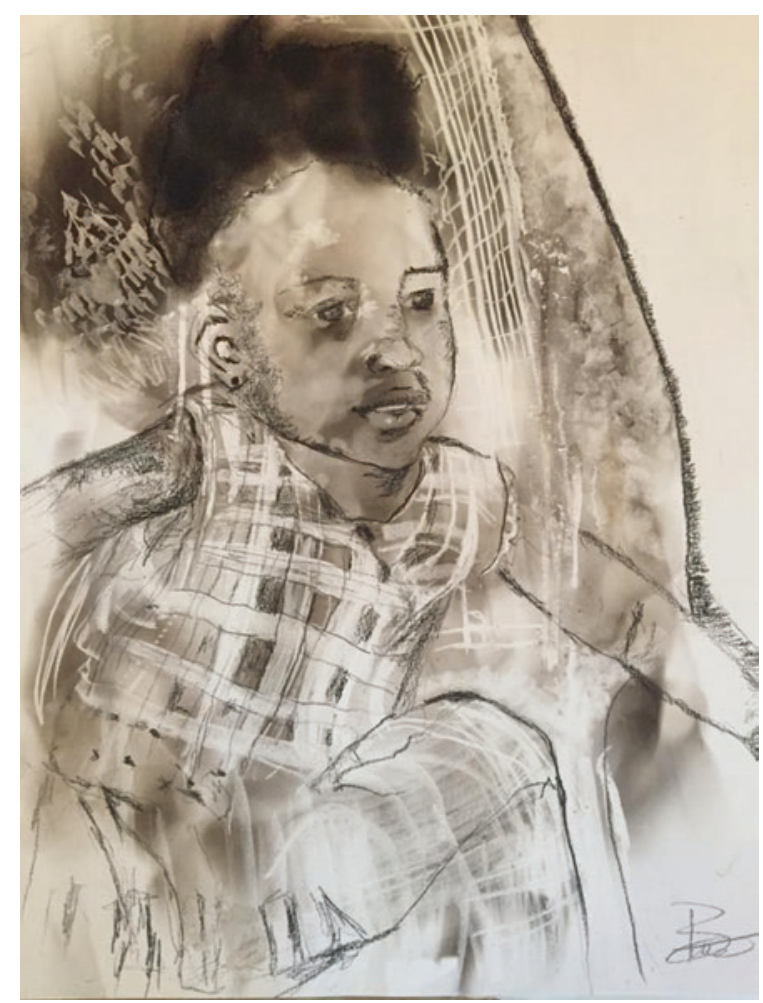

Fig. 9.5 "Of Another Time When I Existed," 2020. Self-portrait drawn in smoke and charcoal on paper

"Old Masters" are seen in the context of moving forward in time through different life stages, Tau decides here to move backward in time, and thus operate through the lens of memory. She chooses to use the autofictional approach of imitating a former practice of self-portraiture and subverting this narration by reversing the sequence in which her self-portraits are made, thereby inverting the practice of the "Old Masters" to suit her personal narrative.

Memory operates on two different levels in this image: first, we observe its visual trace in the photograph that Tau uses as her source material, the physical manifestation of the memory, so to speak. Second, Tau stages the act of remembering an event from her childhood in how she recreates the 
image in a different medium. This self-portrait, unlike many of Tau's other works, is made using candle smoke and charcoal. The image forms part of a series of candle smoke and charcoal drawings for a group exhibition at Galerie L'App'Art in Périgueux, France (2020). In her artist statement to the gallery, Tau explains the creative process behind the series in the following terms:

The Smoke Drawings are a method of accessing memories through imagery. These are inclusive of cultural memories. Smoke is a tentative, unstable medium, similar to how we access our memories. The fragility involved in the process of accessing memory is the motivation behind incorporating this fragile medium. The elements of charcoal used to reinforce lines in the drawings are symbolic of the methods used to reinforce images in our memories, where we relive and attempt to commemorate moments in our past, attempting to burnish them into our recollection forever. This series is a way of me trying to hold onto and commemorate memories of current happenings and the past.

Here, Tau addresses the tentative nature of autofiction and selfportraiture as she highlights the shared use of memory in self-writing and self-depiction. In making memory the medium through which she narrates the self, Tau highlights that the foundation of such a narrative is inherently unstable and fluctuating. She implies that one can never fully trust the legitimacy of this account, as it will fluctuate and distort just as memories do. The idea that memories are unreliable and distorted can be analyzed further with reference to Freud's notion of the screen memory:

$[\mathrm{T}]$ o fictionalize one's self is essentially an autofictional enterprise. If we are to believe Freud's theory on screen memories, according to which the memories we have of our childhood are only screens that hide repressed contents, autofiction would in Laouyen's terms be a more authentic way. Authenticity is always related to subjectivity, and "lies and fiction can give a truer picture than autobiography." (Sébastien Hubier cited in Ferreira-Meyers 2015, 214)

Below is an example of how Tau uses the autofictional in her work to play with the memory of her "self," and how the fictionalization of an aspect of her childhood points to repressed content.

In "Of Another Time When I Existed" (2020), Tau depicts herself at the age of five. She wears a "Sunday dress" (one that would be based, typically, on a semi-formal European design), which required the five-year-old 
Tau to assume a polished and lady-like demeanor. In the image we see a young Tau crouched on a chair, poised to launch herself from it, and thus disregarding the required "decorum" of her dress. Contrary to the elegant and adult-like demeanor that her outfit demands, the rebellious position that Tau depicts shows the child straining against normative expectations of both behavior and appearance, the trappings of which point to European norms. For the child's caretakers, who have sought here to culturally "polish" her, the primary source of shame is her disheveled Afro (ruffled during her playtime), which Tau draws using smoke. Culturally, the young Tau's untidy Afro symbolized a child who was ungroomed, and it is no coincidence that the trappings of the cultural regulations toward which Tau points in this image are European. The purity and innocence in a child's defiance of such regulations is what she seeks to remember of herself and preserve through this image. At the same time, she gives a subtle reminder of the fragility of this memory by representing it through a medium that could very easily disintegrate, just as the memory itself does with time (Wixted and Ebbesen 1991, 409-415). The blurry appearance of the smoke medium visually represents the opacity of autofictional practice. While it gives the impression of translucence or even transparency, upon closer inspection one discovers that it is impossible to see fully through the medium.

\section{The “Trickery" Revealed}

As autofiction takes place between autobiography and fiction-whether shifting between the two or situated as a midway point-it has the unique feature of maintaining a sense of transparency about the possible "trickery" which occurs in the process.

"I knew who I was this morning, but I've changed a few times since then" (Fig. 9.6) is a self-portrait that Tau took in Saint-Émilion, France, where she resided in 2020. Saint-Émilion was declared a UNESCO World Heritage site in 1999 due to its viticulture and historic architecture: all the buildings have a limestone structure, which has been a trademark of the village since the eleventh century (UNESCO n.d.). The composition consists of three layers, superimposed onto each other. The first layer is a façade of a limestone building in Saint-Émilion, the second is Tau herself taking the self-portrait, and the third is her artist's studio. The image testifies to Tau's desire to partake in the history of this space and to integrate as a resident during her stay. Revealing her studio space in the third layer 


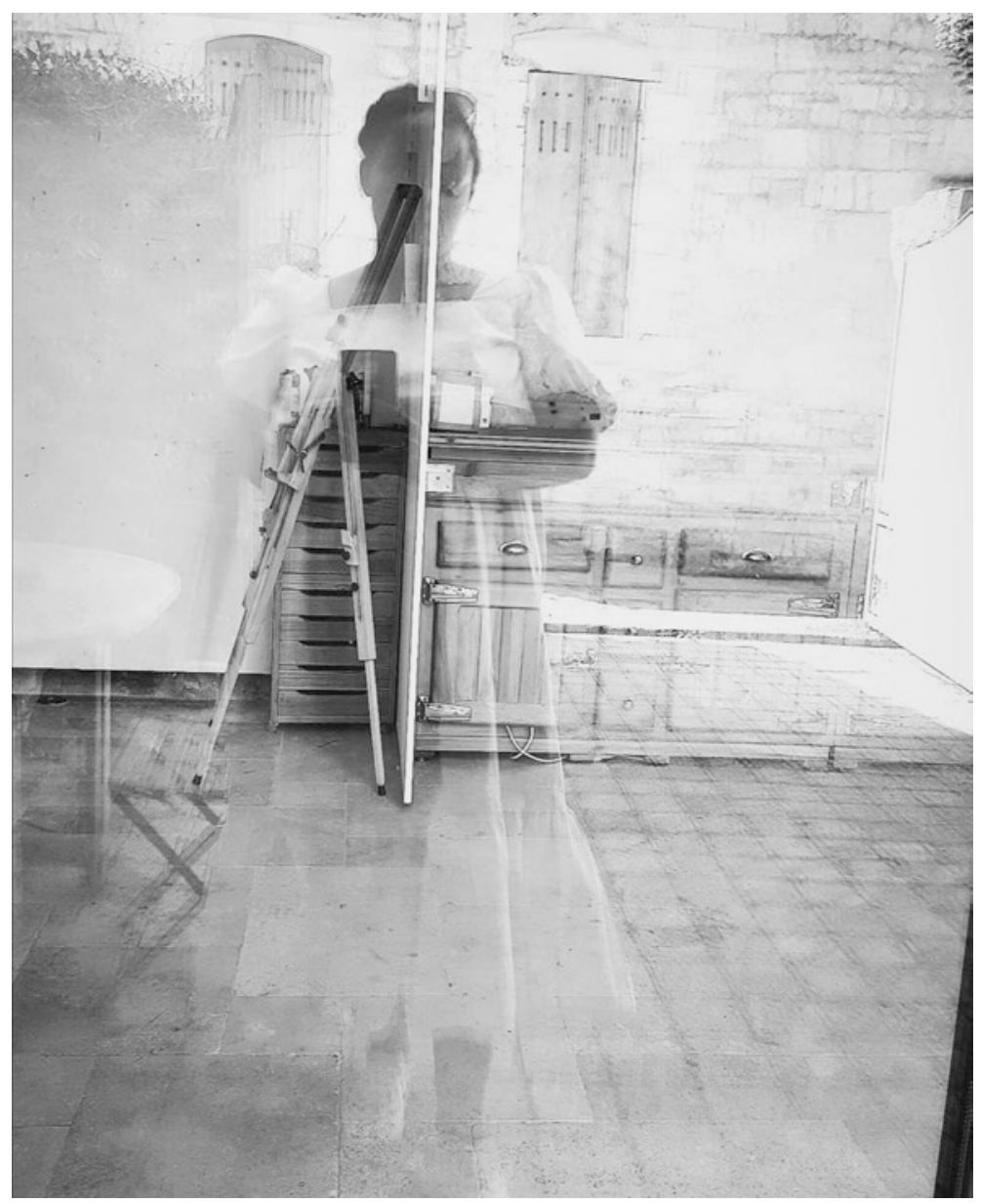

Fig. 9.6 "I knew who I was this morning, but I've changed a few times since then" (After Lewis Carroll), 2020. Digital Self-Portrait

of the image offers a glimpse "behind the curtain" or "through the smokescreen" that she has placed in the performative space of the self-portrait. Contrary to works like "The Look of Reading (After Garret Stewart)" (Fig. 9.1), Tau adopts the process of layering and superimposition when considering her cultural identity rather than moving between identities. 
The fusing of all the apparent layers together in such a translucent manner allows for more depth in the presentation of the cultural "self." Here, Tau can identify as a new Francophone, or one who participates in the historical, cultural space she finds herself in, and simultaneously accommodate her other variations of "self." Using imaginative visual symbols, such as the translucent "smokescreen," as autofictional tools to integrate herself into the space, Tau creates a narrative where she has cultural ties to the space in which she finds herself. She does this by attempting to visually fuse herself with the landscape, using the glass in the image as a translucent binding element for her reflection and the reflection of the buildings in the background.

\section{UNREQUITED Love}

The desire for inclusion in a historical-cultural narrative that runs throughout Tau's oeuvre conjures the notion of an unrequited love between Africa and Europe. It is this same desire that underpins the work of many African artists who, like Tau, do not form part of the cultural and racial group that has been institutionalized in the globally acclaimed visual art narrative, and who use their creative practice to figuratively insert themselves therein. This impulse toward self-inscription illuminates the painful reality of an unreciprocated reverence toward European subjects, as ethnic groups which fall outside of the Eurocentric norm are not given the same institutional value within the visual arts. While the white European body is omnipresent in the acclaimed tradition of self-portraiture, the ethnic body is virtually invisible. We see this in particular in the lack of representations of black protagonists in the canon. American self-portrait photographer Carrie Mae Weems discusses the idea of "unrequited love" in relation to the striking lack of representations of the black body in traditional Western art in her interview with The National Gallery of Art, which preceded her participation in the Diamonstein-Spielvogel Lecture Series in 2015: she speaks of "unrequited love" toward the black body as subject matter in the works of the "Old Masters." The starting point for Weems's discussion is her own relationship as a visual artist to the representation of the black body in traditional Western art. The black body, she argues, serves as a background figure or as decorative to white protagonists in the work of the Old Masters. As a means of exposing and resisting this imbalanced representation, Weems choose to use fictionalized techniques of either inserting the left-out subjects into contemporary visual narratives of the 
classic paintings, or drawing figures who were originally part of the background into the foreground of the image. Weems describes this practice in the following terms:

At a certain point you realise that I'm not his [referring to Manet as an example] subject. This historical body [the black body] has not been the subject of these great painters. From the nineteenth century, to the twentieth century, even moving on to the twenty-first century, it is not a part of their imagination. It is not a part of their fantasy ... but of course, art has a lot to do with imagining the unimaginable. (Kleinburg 2015)

In Tau's own quest for multicultural representation in the visual art canon, she identifies one painting in which the black female is presented as the main protagonist: "Portrait d'une négresse" (Portrait of a Negress), recently renamed "Portrait de Madeleine" (Portrait of Madeleine), by Marie-Guillemine Benoist. The recent name change of the work points toward an effort to personalize the portrait, to portray its subject as an individual rather than as a generic representative of a racial group. The name change also demonstrates a significant effort to humanize the subject by changing the word "négresse," which was seen as a derogatory term, to the subject's own name. When analyzing the image, as well as its countless reproductions by other artists, it quickly becomes apparent that one of the most identifiable qualities of the portrayed subject is her toplessness. Her bare breasts, for this reason, seem to become the key "qualifying" factor for her appearance as protagonist in this portrait. In her discussion of "Portrait de Madeleine," Cécile Bishop describes two initial reactions to Benoist's controversial work at the time. Created in 1800 between the first abolition of slavery in France and its reinstatement in 1802, responses to this work from art historians and critics were divided between praising the humanizing quality of the image, as a rare example of a portrait which focused on a black woman, and critiquing its objectification of the black body (Bishop 2019, 1).

Perplexed by the seeming prerequisite of toplessness for the entry of the black female body into this visual narrative, Tau participates in the recurring tradition of reinterpreting this painting in her work as many other artists have done before her. "Portrait de Madeleine" is the only representation of a black female as protagonist in the Louvre and, as a result, it has been identified as an important visual reference for black artists when negotiating their relationship with the canon. "Amour 
non partagé" (Unrequited Love) (Fig. 9.8) is the final self-portrait in Tau's 2020 series. It was taken in the courtyard outside of her residence in Saint-Émilion, as a closing ode to a language and culture that she reveres.

In a similar manner to Carrie Mae Weems, Tau exposes and resists the lack of reciprocity in the affection for Western languages and cultures in this image. She does so by projecting her body onto the sole portrayal of the black female as protagonist in canonical portraiture, playing the role of the "Negress" in Benoist's image. Tau wears her traditional Sesotho "seshweshwe" dress, as a final reminder of home and her Sesotho identity before "stripping bare" to a historical European landscape. Tau demonstrates the dual nature of autofiction in this work by layering the aspects of self-projection onto the French landscape. Throughout her studio

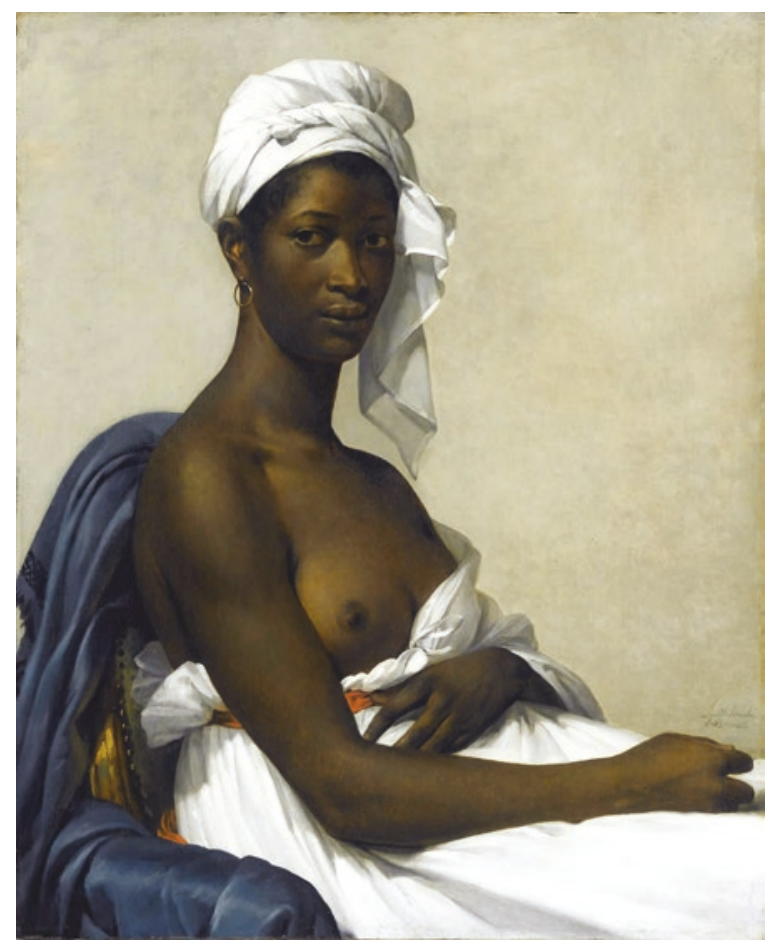

Fig. 9.7 "Portrait de Madeleine" (formerly known as Portrait d'une négresse), Marie-Guillemine Benoist, 1800. Louvre Museum, Paris. Picture in public domain 
practice, Tau recognizes the "duality" in autofiction which allows an artist (or writer) to present the self from an imaginative perspective, but which simultaneously exposes a sense of vulnerability as they reveal existing imaginative fantasies using the fictional platform that autofiction implies. Formal elements of art such as framing and composition provide a desired perspective of the captured scene to the viewer, in this case, a perspective where one sees a close-up image of Tau and very little of her surrounding environment. In this way, Tau is able to juxtapose her African cultural roots with the European landscape in which she finds herself. As an ode to Madeleine, who is depicted in Benoist's work, Tau endeavors to re-enact and remind us of the occasion when this European landscape, to which the canon of self-portraiture has long been limited, invited the black female body into its visual narrative. In this image Tau crops her face out of the image to offer her body as a universal representation of a black woman. Contrary to the effect of the personalization of Madeleine in Benoist's work (Fig. 9.7), Tau emphasizes the anonymity or "invisible" nature of the black female in Western presentations. By way of this anonymous posture, she appropriates the objectifying Western gaze onto the black female

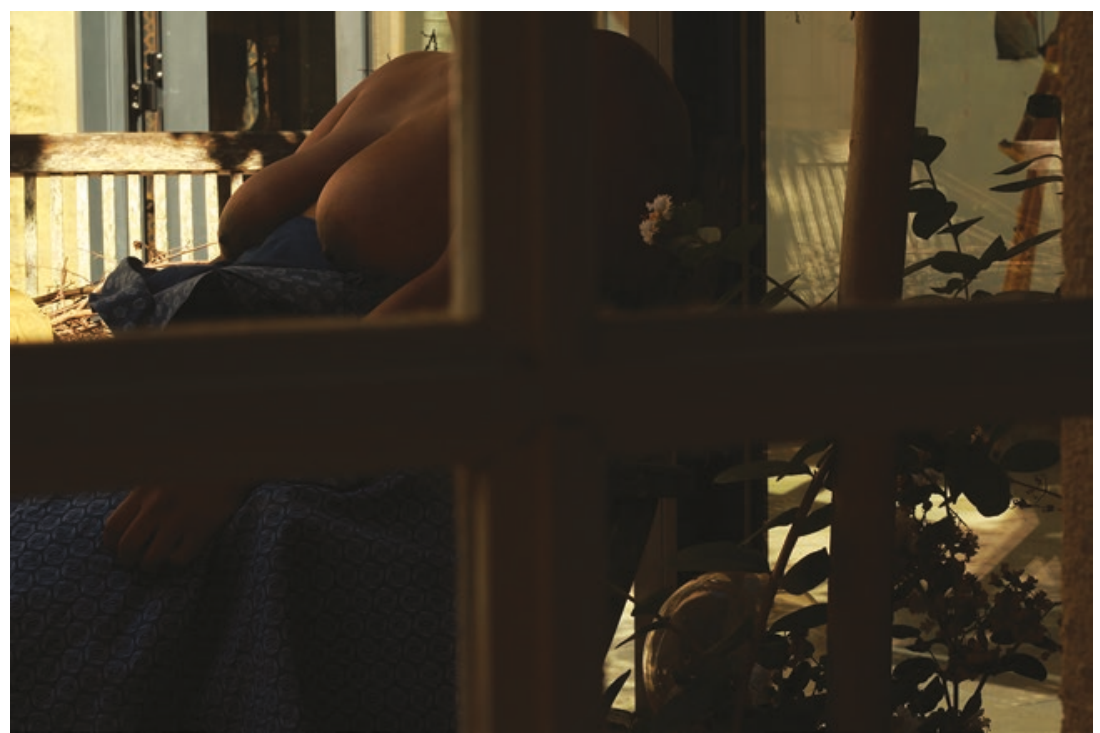

Fig. 9.8 “Amour non partagé” (Unrequited Love), 2020. Digital Self-Portrait 
body, using the practice of self-portraiture to position herself as at once the subject to be consumed and the voyeur who consumes.

Finally, Tau draws attention to the windowpane through which this self-portrait is taken, a lens reminiscent of the viewfinder of a camera and which reinforces the virtual distance between viewer and subject. She makes subtle reference in this regard to the creation and staging of the image, as well as to the inaccessibility of the subject. By creating a barrier between the viewer and herself as subject, she creates an awareness of the spatiality of the photograph. Two spaces or "positions" become prevalent: the outside, which is represented by the position that Tau occupies in the courtyard, and the inside, which is occupied by the viewer, who is positioned where Tau's camera is on the inside of the residence, looking out toward her as voyeur. Drawing here on the social connotations of being an "insider" versus an "outsider," Tau brings the notion of inclusion to the fore. In this photograph, Tau, in her seshweshwe dress within a European landscape, and placed on the physical exterior, resembles an outsider to Western culture. The viewer, on the other hand, automatically occupies the position on the physical and metaphorical "inside" of the European culture, by way of the perspective provided through the camera's lens. By situating the viewer on the virtual "inside," an uncommon viewpoint, and placing herself on the exterior, Tau implies the power dynamic between viewer and subject, one of socio-cultural position and of authoritative gaze, due to the freedom to look at her body without the opposition of the subject who looks back at the viewer, challenging the voyeur's consumption of her body. Unlike the original portrait by Benoist, Tau removes the face of the subject, making her more vulnerable and accessible to the viewer's consumption. This, in turn, functions as a subversive displacement mechanism, as the "inside" position makes the viewer painfully aware that they are a voyeur to a vulnerable subject.

\section{“Re-presentation": An Autofictional Strategy for Alternate Presentations of the "Self"}

Tau's oeuvre showcases some of the key ways in which autofictional techniques are used to create an imaginative role-play in which an artist is able to project herself into varying lingual and cultural identities. In visual practice, these autofictional techniques may take the form of a "smokescreen," which blurs the lines between these identities and allows the artist 
to move between them. Language acquisition and assimilation into dominant cultures pose a potentially significant challenge to those who belong to external cultural groups. The concept of sacrifice comes into view where an aspiring polyglot or master of various cultural identities is left to question whether creating the space to adopt new cultural identities truly requires the erasure of the former identities. The endeavor to combine lingual identities that are on opposing ends of the cultural spectrum, such as Sesotho and French, in a single manifestation of the "self" necessitates an alternative lens through which to view the self. The use of the autofictional in contemporary self-portraiture provides this lens.

The unsettling nature of autofiction, in which truth and fiction are uncomfortably juxtaposed, invites us to question the former association between self-representation and truth, an association that is perhaps even more persistent in visual than in literary depictions of the self. Through the role-play it foregrounds in self-representation, the autofictional undoes former solidified narratives based on the self and illuminates the multiple perspectives and subjective angles from which the self is always seen. Crucially, it creates a space in which alternative narratives of self can coexist. Adopting this autofictional approach is a step toward establishing more cultural inclusion and social cohesion in the tradition of self-portraiture, by challenging the pre-structured and compartmentalized views on self and singular cultural identity.

\section{Works Cited}

Ahmed, Maaheen. 2014. The Art of Splicing: Autofiction in Words and Images. International Journal of Comic Art 16 (1): 322-338.

Avedon, Richard. 1993. An Autobiography. New York: Random House.

Bhabha, Homi. 1994. The Location of Culture. London: Routledge.

Bishop, Cécile. 2019. Portraiture, race, and subjectivity: the opacity of MarieGuillemine Benoist's Portrait d'une négresse. In Word and Image (35): 1-11. de Bloois, Joost. 2007. Introduction. The Artists Formerly Known As... Or, the Loose End of Conceptual Art and the Possibilities of 'Visual Autofiction.' Image and Narrative 8 (19): n.p.

Condé, Maryse. 2014. La Vie sans fards. POCKET Publications.

Crozier, W. Ray., and Paul Greenhalgh. 1988. Self-Portraits as Presentations of Self. Leonardo 21 (1): 29-33.

Ferreira-Meyers, Karen. 2012. Autofiction: 'Imaginaire' and Reality, an Interesting Mix Leading to the Illusion of a Genre? Caietele Echinox 23: 103-116. 
2015. Autobiography and Autofiction: No Need to Fight for a Place in the Limelight, There Is Space Enough for Both of These Concepts. In Writing the Self: Essays on Autobiography and Autofiction, ed. Kerstin Shands, Giulia Grillo Mikrut, Dipti R. Pattanaik, and Karen Ferreira-Meyers, 203-218. Huddinge: Södertörns högskola.

- 2018. Does Autofiction Belong to French or Francophone Authors and Readers Only? In Autofiction in English, ed. Hywel Dix, 27-48. Cham: Palgrave Macmillan.

Fishman, Joshua A. 1996. What Do You Lose When You Lose Your Language? In Stabilizing Indigenous Languages, ed. Gina Cantoni, 71-81. Flagstaff, AZ: Northern Arizona University.

Halliday, Michael Alexander Kirkwood. 1978. Language as Social Semiotic: The Social Interpretation of Language and Meaning. London: Edward Arnold.

Kleinburg, Jerry. 2015. Diamonstein-Spielvogel Lecture Series: Carrie Mae Weems. Last updated September 15, 2015. https://www.nga.gov/audio-video/ diamonstein-spielvogel/diamonstein-spielvogel-weems.html. Accessed Apr 6, 2021.

Miller, Stephen Paul. 1993. 'Self-Portrait in a Convex Mirror' the Watergate Affair, and Johns's Crosshatch Paintings: Surveillance and Reality-Testing in the Mid-Seventies. Boundary 220 (2): 84-115.

Museum of Modern Art Glossary. 2021. Self-Portraiture. https://www.moma. org/collection/terms/self-portrait. Accessed March 20, 2021.

Smith, David R. 2001. Renaissance Self-Portraiture: The Visual Construction of Identity and the Social Status of the Artist. The Art Bulletin 83 (2): 354-357.

Stewart, Garrett. 2009. The Look of Reading. Chicago: University of Chicago Press. Tau, Bontle. 2018. Multilingual role-play and authentic self. An autofiction by Bontle Tau. University of the Free State.

UNESCO. n.d. Jurisdiction of Saint-Emilion. In World Heritage List. https:// whc.unesco.org/en/list/932. Accessed Apr 6, 2021.

Wixted, John T., and Ebbe B. Ebbesen. 1991. On the Form of Forgetting. Psychological Science 2 (6): 409-415.

Woods-Marsden, Joanna. 1998. Renaissance Self-portraiture: The Visual Construction of Identity and the Social Status of the Artist. Yale University Press. 
Open Access This chapter is licensed under the terms of the Creative Commons Attribution 4.0 International License (http://creativecommons.org/licenses/ by $/ 4.0 /)$, which permits use, sharing, adaptation, distribution and reproduction in any medium or format, as long as you give appropriate credit to the original author(s) and the source, provide a link to the Creative Commons licence and indicate if changes were made.

The images or other third party material in this chapter are included in the chapter's Creative Commons licence, unless indicated otherwise in a credit line to the material. If material is not included in the chapter's Creative Commons licence and your intended use is not permitted by statutory regulation or exceeds the permitted use, you will need to obtain permission directly from the copyright holder. 